\title{
Recycling of Pure Magnesium Chips by Cold Press and Hot Extrusion Processes
}

\author{
H. Mindivan ${ }^{a, *}$, N. TASKIN ${ }^{b}$ AND E.S. KAYALI ${ }^{b}$ \\ ${ }^{a}$ Ataturk University, Engineering Faculty, Department of Metallurgy and Materials Engineering, Erzurum, Turkey \\ ${ }^{b}$ Istanbul Technical University, Chemical and Metallurgical Engineering Faculty, Metallurgical and Materials \\ Engineering Department, Istanbul, Turkey
}

\begin{abstract}
This study aims to recycle pure magnesium chips by a two-stage mechanical processing method. In the present study, the feasibility of recycling pure magnesium chips with the help of commercially pure magnesium powder was investigated. For this study, the magnesium chips mixed with different amount of magnesium powders in the range of 25-75 wt\%, after mixing by hand and cold press, are subjected to hot extrusion to provide homogeneous microstructure. Furthermore, the effect of magnesium powder and their amounts on the mechanical properties and corrosion behaviour of the recycled magnesium alloys were studied. The results of the mechanical and corrosion test showed that the hardness and compressive yield strength decreased with increasing chip content, while increase in the chip weight fraction in the initial mixture resulted in a significant increase of corrosion resistance.
\end{abstract}

DOI: $10.12693 /$ APhysPolA.125.429

PACS: 72.15.Eb, 81.70.Bt, 82.45.Bb

\section{Introduction}

Magnesium alloys, owing to their high specific stiffness, high specific strength, excellent castability and good recycling ability and because they are lightweight, are increasingly replacing conventional materials like steel or aluminium components in many applications. Accompanying this consumption increase, an increase in industrial wastes and product replacement poses a problem on the environment, which can be solved through recycling for the sustainable society [1-3]. Presently, metallic scraps can usually be re-melted to cast into ingot for subsequent processing. Nevertheless, this method may not be efficient for magnesium alloys because magnesium chips are prone to oxidation. Therefore, solid state recycling is proposed as an alternative method of recycling magnesium alloys. However, magnesium alloy chips were prone to form a compact oxide layer since magnesium alloys were readily oxidised. But, oxide layers could prohibit the fine bonding between the chips in the extrusion process. With the objective of avoiding the residual porosity and imperfect bonding between the chips, magnesium powder was introduced in the recycled product. This was achieved by mixing magnesium chips with magnesium powder as a binder phase and by cold pressing followed by hot extrusion.

\section{Materials and experimental procedures}

The starting magnesium chips with sizes of $(5-10) \times$ $1.5 \times 0.8 \mathrm{~mm}^{3}$ were blended with different weight fractions $(25,50$, and 75$)$ of magnesium powder $(\approx 16 \mu \mathrm{m})$ by hand. After blending, the chip/powder mixture was pressed into a die to form a compact shape of $30 \mathrm{~mm}$

*corresponding author; e-mail: hmindivan@hotmail.com diameter and $30 \mathrm{~mm}$ length under $700 \mathrm{MPa}$ pressure, using a press machine of 100 tons capacity. Finally, these compacts were hot-extruded at $350^{\circ} \mathrm{C}$ with a reduction ratio of 9:1, to form rods of $10 \mathrm{~mm}$ diameter.

In accordance with the standard metallographic procedure, which includes a grinding process up to 1200 mesh and a polishing process with alumina solution conducted on the recycled magnesium alloys, microstructural analysis on the prepared alloys was conducted using a light optical microscope (LOM). The volume porosity of the recycled alloys that were fabricated under different conditions was measured by the Archimedes method using the following equation:

$$
\% \text { porosity }=\frac{\rho_{\text {MgPowder }}-\rho_{\text {RecycledMg }}}{\rho_{\text {MgPowder }}} \times 100,
$$

where $\rho_{\mathrm{MgPowder}}$ is the density of the initial magnesium alloy without chip and $\rho_{\text {RecycledMg }}$ is the density of the recycled magnesium alloys containing chip.

The mechanical property studies of the recycled alloys were determined by carrying out hardness measurements and compression tests. Hardness survey was measured on Shimadzu HMV2 microhardness tester by applying indentation load of $200 \mathrm{~g}$ with a Vickers indenter. At least, ten successive measurements were made for the recycled alloys including different amounts of chips. Round samples with $20 \mathrm{~mm}$ of length and $10 \mathrm{~mm}$ of diameter were tested by a Dartec Universal testing machine at a crosshead speed of $1 \mathrm{~mm} / \mathrm{min}$ to determine the compression behaviour of the recycled alloys. The results of the compression tests were compiled by averaging the decision of three samples.

The corrosion tests were evaluated by both weight loss measurements and electrochemical tests. Each data point for both weight loss measurement and electrochemical test represents the average of three different measurements. For the weight loss-measuring test, square 
shape samples with an average size of $2 \mathrm{~mm} \times 2 \mathrm{~mm}$ were immersed in $3.5 \% \mathrm{NaCl}$ solution in a Pyrex glass cell exposed to atmospheric air for $36 \mathrm{~h}$. The amount of solution in the baker was estimated by taking into account the surface area of the samples as $0.6 \mathrm{ml} / \mathrm{mm}^{2}$.

The samples, which were taken out of the solution at certain intervals during the corrosion experiments, were ultrasonically cleaned in distilled water and alcohol, after which they were weighed using a $0.1 \mathrm{mg}$ sensitive electronic scale. The normalised weight loss values of the recycled alloys were calculated in the unit of $\mathrm{g} / \mathrm{cm}^{2}$ by dividing the weight loss of the each sample by their initial total surface area. Finally, the surface images of the corroded samples were examined using a scanning electron microscope (SEM) in order to determine the morphology of the developed corrosion. For the electrochemical corrosion tests, samples were attached to a copper wire and embedded into an epoxy resin holder, to allow an open surface area of $0.15 \mathrm{~cm}^{2}$. The potentiodynamic polarisation measurement was carried out using a Gamry model PC4/300 mA potentiostat/galvanostat controlled by a computer with DC 105 Corrosion analysis software. All the corrosion experiments were performed at room temperature in a glass cell containing $3.5 \% \mathrm{NaCl}$ solution. Each polarisation experiment was carried out holding the electrode for $45 \mathrm{~min}$ at open circuit potential $\left(E_{0}\right)$ to allow steady-state to be achieved. Potentiodynamic polarization curves were generated by sweeping the potential from cathodic to anodic direction at a scan rate of $1 \mathrm{mV} \mathrm{s}^{-1}$, starting from -0.1 up to $+0.4 \mathrm{~V}$. Corrosion potentials $\left(E_{\text {corr }}\right)$ and corrosion current densities $\left(i_{\text {corr }}\right)$ were calculated using a Tafel type fit in the software.

\section{Results and discussion}

Metallurgical microstructures of the recycled alloys with $25 \mathrm{wt} \%$ and $100 \mathrm{wt} \%$ chip are shown in Fig. 1. All micrographs were taken for the plane perpendicular and parallel to the extrusion direction. Chips in the recycled alloys exhibited an elongated fibre-like structure. Some long crooked black lines could be seen in the metallurgical microstructures, as shown with the white arrow. These black lines by an EDX analysis were the bonding interface of the original chips including plenty of oxygen contents. This indicates that oxidation layers on the chips were not completely broken into pieces by compressive and shear forces with the extrusion ratio of 9:1.

The results of the room temperature mechanical test and volume porosities of the recycled alloys are plotted in Fig. 2, against the chip content of the recycled alloys. It is clear that the quality of the recycled alloys ultimately depends on the chip content and the chip content is one of the important factors in the control of the oxide concentration and porosity level. During the hot extrusion of the recycled alloys containing light-oxide (e.g., the recycled alloys with $25 \mathrm{wt} \%$ and $50 \mathrm{wt} \%$ chips), atoms diffuse over the entire area of contact between the particles, whereas in the case of the recycled alloys containing heavy-oxide (e.g., the recycled alloys with $75 \mathrm{wt} \%$ and $100 \mathrm{wt} \%$ chips), atoms diffuse only through the oxide-free

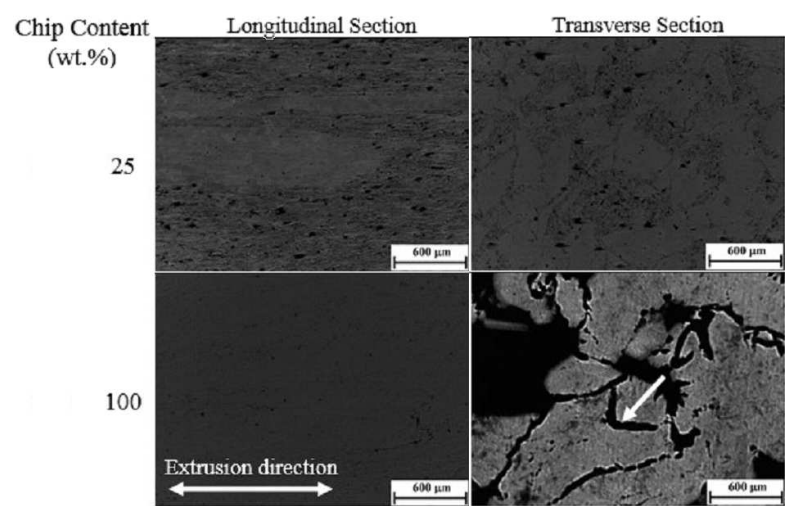

Fig. 1. Unetched optical micrographs of longitudinal and transverse sections for the recycled alloys. The arrow indicates the site for void and bonding interface between chips.

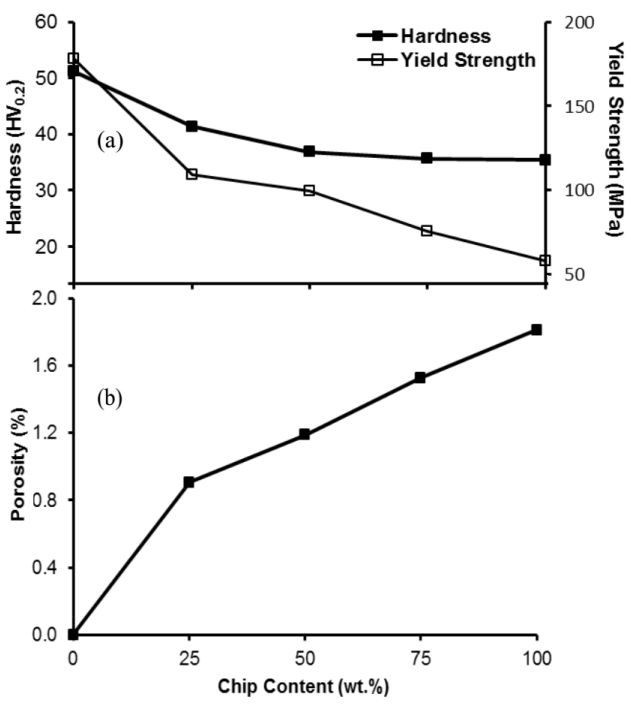

Fig. 2. The effect of chip content on the (a) hardness, compressive yield strength and (b) porosity of the recycled alloys fabricated using different chip weight fractions in the initial mixture.

cracks formed during the plastic deformation of particles accompanying the compression of the chip/powder mixture. Comparing the test results reveals that the former mechanism was not effective in bonding of the chips in the recycled alloys with high chip content to each other and hence the recycled alloys with $75 \mathrm{wt} \%$ and $100 \mathrm{wt} \%$ chips produced had low mechanical strength. It is thought that the decrease in the hardness and compressive yield strength with increase in the amount of chips added to the recycled alloy is dependent on the poor wettability of chips with each other due to the presence of oxide on the chip, in addition to the higher porosity (Fig. 2b).

Figure 3 illustrates the change in weight loss against time for the recycled alloys subjected to corrosion, by being dipped into a $3.5 \% \mathrm{NaCl}$ solution. The weight loss of the recycled alloys showed a consistent increase against time. Chip addition to alloys generally reduced 


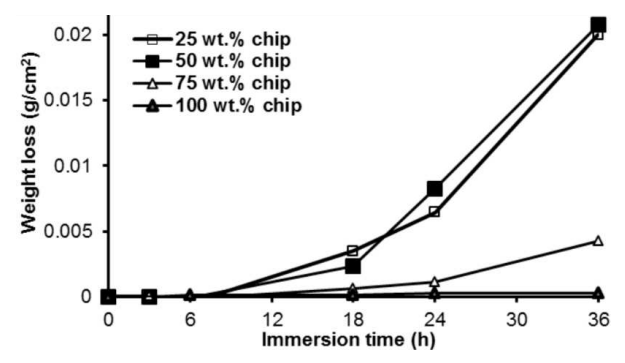

Fig. 3. Weight loss of the recycled alloys with respect to the test period.

the weight loss. The recycled alloy with the highest chip content presented the lowest weight loss.

Figure 4 shows the surface morphologies of the recycled alloys with $25 \mathrm{wt} \%$ and $100 \mathrm{wt} \%$ chips after dipping corrosion. The behaviour of the recycled alloy with $25 \mathrm{wt} \%$ chips was different than that of the other recycled alloy. Many pits were found on the surface of the recycled alloy containing $25 \mathrm{wt} \%$ chips and the surface topography of this alloy is rough (Fig. 4a). In contrast, most areas of the recycled alloy with $100 \mathrm{wt} \%$ chips are not corroded or only a few areas are slightly corroded as shown in Fig. 4 b. The results also indicate that upon increasing the chip content, the surfaces of the recycled alloy remain more and more corrosion free.

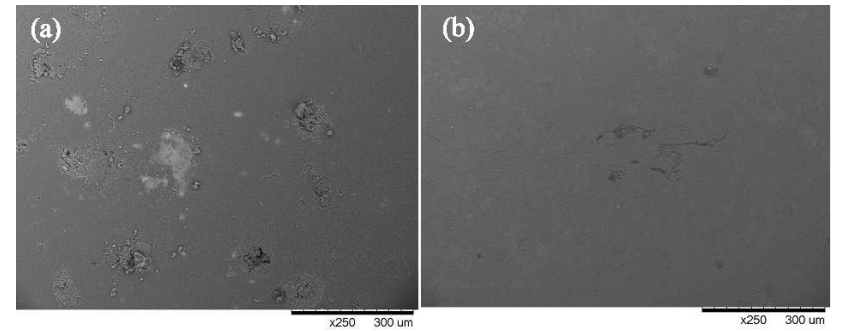

Fig. 4. SEM morphologies of corrosion surface of the recycled alloys with (a) $25 \mathrm{wt} \%$ chips and (b) $100 \mathrm{wt} \%$ chips.

Figure 5 illustrates the potentiodynamic polarisation curves of the recycled alloys with $25 \mathrm{wt} \%$ and $100 \mathrm{wt} \%$ chips, conducted in the same solution. It was found that the Tafel curve for the alloy with 25 wt\% chips exhibits a corrosion potential at $-1.550 \mathrm{~V}$, which is positively shifted about $60 \mathrm{~V}$ relative to the alloy with $100 \mathrm{wt} \%$ chips with corrosion potential at $-1.610 \mathrm{~V}$. Meanwhile, the corrosion current density $\left(i_{\text {corr }}\right)$ of the alloy with 100 wt\% chips was $91.1 \times 10^{-6} \mathrm{~A} \mathrm{~cm}^{-2}$, approximately eight times lower than that of the alloy with $25 \mathrm{wt} \%$ chips $\left(707 \times 10^{-6} \mathrm{~A} \mathrm{~cm}^{-2}\right)$. The polarisation test results lead directly to the conclusion that the corrosion resistance of the recycled alloy containing high chip was better than that of the recycled alloys with low chip content, which was in good agreement with the results of weight loss measurements. It was thought that the increase in corrosion resistance with increase in chip content was attributed to the oxides on the chips surface formed networks of oxide layers parallel to the extrusion direction. A tube-like oxide layer could restrict the movement of metal ions from the metal surface to the solution [4].

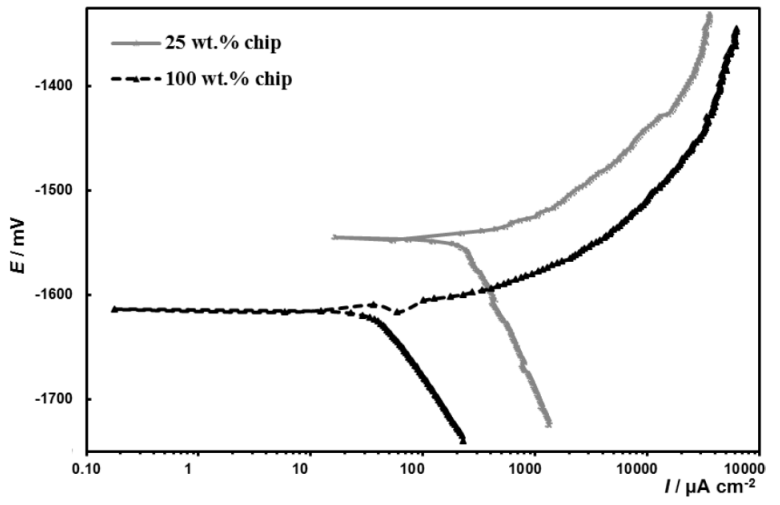

Fig. 5. Potentiodynamic polarisation curves for the recycled alloys in $3.5 \% \mathrm{NaCl}$ solution.

\section{Conclusion}

Pure magnesium chips mixed with $25 \mathrm{wt} \%, 50 \mathrm{wt} \%$ and 75 wt $\%$ magnesium powder were recycled successfully by cold pressing followed by hot extrusion. Microstructure characterisation studies revealed an elongated fibre-like structure of chips in the recycled alloys and the presence of minimal micro-porosity in the recycled alloy with a decrease in chip content. The hardness and compressive yield strength of the recycled alloys tested decreased with increase in the amount of chips added. However, the maximum effective increase in corrosion resistance was exhibited by the recycled alloy with 100 wt\% chips.

\section{Acknowledgments}

The financial support of the research foundation of Ataturk University is gratefully acknowledged. The authors would also like to thank the Metallurgical and Materials Engineering Department of Istanbul Technical University for their technical support.

\section{References}

[1] T. Zhang, Z. Ji, S. Wu, Mater. Design 32, 2742 (2011).

[2] H.Ji. Mao-Liang, C. Ze-Sheng, W. Xiao-Yu, D. Qudong, T. Wen-Jiang, Nonferr. Metal. Soc. 22, 68 (2012).

[3] J. Miao, B. Ye, Q. Wang, T. Peng, J. Alloys. Comp. 561, 184 (2013).

[4] Y. Chino, T. Hoshika, M. Mabuchi, Mater. Sci. Eng. A Struct. 435-436, 275 (2006). 